Summer 2013

\title{
We and Cyberlaw: The Spatial Unity of Constitutional Orders
}

Hans Lindahl

Tilburg University, lindahl@uvt.nl

Follow this and additional works at: https://www.repository.law.indiana.edu/ijgls

Part of the Constitutional Law Commons, International Law Commons, and the Internet Law

\section{Commons}

\section{Recommended Citation}

Lindahl, Hans (2013) "We and Cyberlaw: The Spatial Unity of Constitutional Orders," Indiana Journal of Global Legal Studies: Vol. 20 : Iss. 2 , Article 7.

Available at: https://www.repository.law.indiana.edu/ijgls/vol20/iss2/7

This Symposium is brought to you for free and open access by the Law School Journals at Digital Repository @ Maurer Law. It has been accepted for inclusion in Indiana Journal of Global Legal Studies by an authorized editor of Digital Repository @ Maurer Law. For more information, please contact rvaughan@indiana.edu.

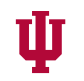

JEROME HALL LAW LIBRARY

INDIANA UNIVERSITY

Maurer School of Law
Bloomington 


\title{
We and Cyberlaw: The Spatial Unity of Constitutional Orders
}

\author{
HANS LINDAHL ${ }^{*}$
}

\begin{abstract}
This paper scrutinizes the fundamental assumption governing Gunther Teubner's theory of societal constitutionalism, namely that societal constitutions are ultimately about the regulation of inclusion and exclusion in global function systems. While endorsing the central role of inclusion/exclusion in constitutions, societal or otherwise, I argue that inclusion and exclusion are primordial categories of collective action, rather than functional categories. As a result, the self-closure which gives rise to a legal collective is spatial as much as it is temporal, and subjective no less than material. Inasmuch as legal orders must establish who ought to do what, where, and when, this entails, or so I argue, that any legal order we could imagine-including a global legal order such as cyberlaw-is necessarily bounded in space, time, content, and membership. This impinges directly on the inclusion/exclusion difference: that there can be no inclusion without exclusion entails, most fundamentally, that there can be no (il)legality without alegality, i.e. comportment that contests, sometimes radically, how a legal order draws the distinction between legality and illegality. In this fundamental sense, all legal orders have an outside-literally. Building on this insight, I suggest that the functional cosmopolitanism advocated by a theory of societal constitutionalism retains a residue of the logic of totalization it seeks to overcome. I conclude by exploring how a first-person plural theory of law both supports and transforms the insight that constitutions regulate the inclusion/exclusion difference by putting into place constitutive and limitative rules.
\end{abstract}

* Chair of Legal Philosophy at Tilburg University, the Netherlands, and Fellow of the Stellenbosch Institute for Advanced Study (STIAS), South Africa. Sections II and III of this paper build on research generously funded by STIAS in 2010 .

Indiana Journal of Global Legal Studies Vol. 20, Issue 2 (2013)

(C) Indiana University Maurer School of Law 


\section{INTRODUCTION}

The theory of societal constitutionalism posits a strong interconnection between constitutions and the inclusion-exclusion difference. Drawing on systems theory, Gunther Teubner's thesis that constitutions are composed of constitutive and limitative rules develops the insight that constitutions regulate the boundary between a function system and its environment. In other words, constitutions regulate the conditions for inclusion in and exclusion from function systems such as politics, law, economics, religion, and science. The globalization of function systems renders this twofold role both visible and urgent: visible because sectors of global society are now organizing themselves under a societal or civil constitution without recourse to or support by political constitutionalism; urgent, because the dark side of the emancipation of function systems from state tutelage is the destructive expansion of systems into their environments. Accordingly, societal self-constitution and self-limitation are the two aspects of boundary regulation, and these two aspects correspond to the inclusive and exclusive roles of constitutions. Societal constitutions include opening up and rendering available to all a communicative medium; societal constitutions exclude laying down the frontier posts beyond which a function system is not to foray into its environment, individual or otherwise.

In an effort to assess this interpretation of constitutionalism, I take my cue from Teubner's claim that it is necessary to think through the conditions governing the constitutionalization of nonstate legal orders. ${ }^{1}$ This claim is, in my view, compelling. Although I will not be arguing this point hereinafter, it would be easy to show that the model of legal order I will be sketching out strongly supports the claim that there is no reason for limiting law to state and international law or even for taking them to be the primordial manifestations of law. I am also happy to accept his insight that constitutions are ultimately about the regulation of inclusion and exclusion. His insistence that the renewal of constitutional theory turns on coming to terms with this difference is a refreshing alternative to the jaded attempts to deal with globalization by projecting the conceptual framework of state constitutionalism onto an all-encompassing global polity. But rather than walking further down the path of societal constitutionalism, I want to pause at this juncture and examine the fundamentals of Teubner's account of constitutions in greater detail. My question is this: Can constitutions be

1. Gunther Teubner, Constitutional Fragments 51-58 (Gareth Norbury trans., 2012). 
about the regulation of inclusion and exclusion in function systems? In other words, can we make constitutional sense of inclusion and exclusion in terms of the boundary between a function system and its environment? More pointedly, in what sense are constitutions about societal self-constitution and self-limitation, and how might this cast new light on the constitutional problem posed by boundaries?

\section{Societal Constitutionalism: A FunCtional READING OF INCLUSION AND EXCLUSION}

In the Storrs Lectures of 2003/2004, Teubner pointed to the quandaries arising from the globalization of digital communication via the Internet. Referring to the well-known Yahoo! case in France, he argued that this and related cases neatly illustrate the continuity and discontinuity of the "constitutional question" going from the heydays of state-constitutionalism in the eighteenth and nineteenth century to the emergence of constitutionalism without a state in our times. Teubner asked, "[h]ow is constitutional theory to respond to the challenge arising from the three current major trends--digitalisation, privatisation and globalisation-for the inclusion/exclusion problem?"2 There is continuity insofar as the difference between inclusion and exclusion remains the central issue to be dealt with by constitutions. There is discontinuity because digitalization, privatization, and globalization drastically change how constitutionalism must deal with inclusion and exclusion. Let us run through how each of these aspects transforms the constitutional question.

Globalization-the globalization of function systems-changes the nature of the constitutional question because inclusion and exclusion cease to be spatially defined categories. In particular, global forms of law can no longer be conceptualized in terms of the inside-outside distinction with regards to the territorial state. ${ }^{3}$ The point is conceptual, not merely empirical. As long as function systems are subject to political regulation, i.e. to regulation by and within a territorial state, it could seem that inclusion and exclusion are primarily spatial categories. By contrast, the globalization of function systems clears the way for understanding inclusion/exclusion as a properly systemic difference. As Niklas Luhmann puts it, "inclusion (and correspondingly exclusion) can only be related to the nature and the way in which people are marked in

2. Gunther Teubner, Societal Constitutionalism: Alternatives to State-Centered Constitutional Theory?, in TRANSNATIONAL GOVERNANCE AND CONSTTTUTIONALISM 3, 4 (Christian Joerges, Inger-Johanne Sand \& Gunther Teubner eds., 2004).

3. See Gunther Teubner, 'Global Bukowina': Legal Pluralism in the World Society, in Global LaW Without a State 3, 14 (Gunther Teubner ed., 1997). 
communication processes, hence are deemed to be relevant." 4 In contrast with the strongly normative stance taken by most social theories, which take for granted that the exclusion of individuals should be overcome in view of securing greater inclusiveness, Luhmann argues that the preferential difference between inclusion and exclusion is a constitutive feature of communication processes. "One can only meaningfully speak of inclusion when there is exclusion."5 By implication,, the globalization of function systems renders inclusion both universal, inasmuch as "the entire population"6 is in principle included in each system, and partial, insofar as it only concerns the dimension of personhood relevant to the system, rather than human beings as such. Consequently, Luhmann and Teubner's defense of the universality of function systems is inimical to a logic of totalization-or so they argue-for systems theory views exclusion as a constitutive feature of function systems, even though the irritability of systems allows for the recalibration of the boundary between what is included and excluded. ${ }^{7}$

I will be more concise as to concerns of privatization, even though this is arguably the dimension of societal constitutionalism that has attracted the greatest attention. Teubner is concerned with showing that the constitutionalization of global sectors of society takes place outside-and even in opposition to-the domain of institutionalized state politics. ${ }^{8}$ It is transnational private actors who, at a considerable distance from both state and international law, are engaged in constitution-making in the twofold sense of self-constitution, which is interpreted as setting up constitutive rules that empower relevant forms of communication, and self-limitation, interpreted as excluding the environment from the corresponding communicative medium. ${ }^{9}$ In a nutshell, privatization changes the constitutional question because what is at stake is no longer the self-constitution and self-limitation of a political community, but rather the self-constitution and self-limitation of global sectors of society, which have traditionally been viewed as "private" from the perspective of political constitutionalism.

4. 6 NiKLAS LUHMANN, SOZIOLOGISCHE AUFKLÄRUNG [SOCIOLOGICAL ENLIGHTENMENT] 229 (4th ed. 2008) (Ger.) (translation by author). For an excellent study on the inclusion/exclusion difference in Luhmann see Antoon Braeckman, Niklas Luhmann's Systems Theoretical Redescription of the Inclusion/Exclusion Debate, 32 PHIL. \& Soc. CRITICISM 65 (2006).

5. LUHMANN, supra note 4 , at 229.

6. TEUBNER, supra note 1 , at 134 .

7. Niklas LuhmanN, Die Gesellschaft DeR Geselischaft [The Community of THE COMMUNITY] 625-26 (1997) (Ger.).

8. TEUBNER, supra note 1 , at 51-57.

9. Id. at $75-87$. 
With regards to digitalization, Teubner insists time and again that reformulating the constitutional question in terms of societal constitutionalism requires a process of generalization and respecification. Generalization is possible because political constitutionalism, qua constitutionalism, puts into place constitutive and limitative rules with respect to a communicative medium (power). The respecification of constitutionalism as societal constitutionalism is realized by positing constitutive and limitative rules with respect to the communicative medium of the system at issue. ${ }^{10}$ As concerns cyberspace, Teubner highlights what is demanded by systemic inclusion when arguing that digitalization, whatever other questions it may raise, calls forth the "more fundamental question of a universal political right of access to digital communication." 11 Obviously, digitalization is but one example of how societal constitutionalism approaches the problem of inclusion/exclusion. What is important is, in each case, a respecification of the boundary between a function system and its environment: politics/environment; economy/environment; law/environment; science/environment; and religion/environment. Fundamental rights play a crucial role in regulating the boundary between a system and its environment inasmuch as they act both as constitutive rules by granting access to the respective communicative medium and as limitative rules by restraining the tendency of the function systems to encroach on individuals and other function systems. ${ }^{12}$

I wrap up this highly abridged presentation of societal constitutionalism by pointing to an important qualification with respect to the relation between constitutionalism and inclusion/exclusion. In effect, while Luhmann insists time and again that inclusion/exclusion is a functional difference, he also points to "the impossibility of function systems to organise themselves." ${ }^{13}$ As a result, the constitutionalization of inclusion and exclusion is not and cannot be oriented towards function systems as such. Teubner phrases this qualification as follows:

10. TEUBNER, supra note 1 , at 132-135.

11. Teubner, supra note 2 , at 4 . One may wonder whether the reference to a "political right" is appropriate here, in view of Teubner's opposition to all attempts to reduce fundamental rights to political rights.

12. "[I] $t$ is the fragmentation of society that is today central to the question of fundamental rights as protective rights. There is not just a single boundary concerning political communication and the individual, guarded by human rights. Instead, the problems arise in numerous social institutions, each forming their own boundaries with their human environments." Gunther Teubner, Transnational Fundamental Rights: Horizontal Effect?, 40 RECHTSFILOSOFIE \& RECHTSTHEORIE [LEGAL PHILOSOPHY \& LEGAL THEORY] 191, 208 (2011) (Neth.).

13. LUHMANN, supra note 7 , at 843 (translation by author). 


\begin{abstract}
Although these processes [of societal constitutionalization] are set in motion by functional differentiation, the constitutionalization process is not directed toward the major function systems themselves. Finance and product markets are globalized, scientific communication takes place at a global level, the systems of communicative media, news agencies, tv, internet transmits news across the whole globe. Despite the operational closure of these world systems ... [they] lack the capacity to take action, to become organized and, therefore to be constitutionalized. The various attempts at global constitutionalism are directed rather at social processes "beneath" the function systems, at formal organizations and at formalized transactions that are not tied to the territorial borders of nation-states. ${ }^{14}$
\end{abstract}

This is a remarkable admission on several counts. First and foremost, if function systems cannot organize themselves, would one not have to conclude that constitutionalizing the inclusion and exclusion difference effectively treats these two terms as categories of action? ${ }^{15}$ More specifically, does not constitutionalization entail that inclusion and exclusion are categories pertaining to collective action? If they are, as I will argue later in this paper, this raises a number of questions about the boundaries that are regulated by societal constitutions: Can we take it for granted that those boundaries are the boundary between a function system and its environment? Moreover, if inclusion and exclusion are categories germane to collective action, what sense are we to make of the "self" of self-constitution and self-limitation, the two dimensions of the process of societal constitutionalization? Would we not have to reintroduce the form of identity that systems theory has attempted to eradicate definitively from society and from sociology, namely, collective selfhood? Would not the "autos" of societal autopoiesis have to mutate, however discretely and even surreptitiously, into the "self" of collective self-regulation, if one wants to make constitutional sense of inclusion and exclusion? If so, what happens to the

14. Gunther Teubner, Constitutionalising Polycontexturality, 20 SOC. \& LEGAL STUD. 210, 221-22 (2011).

15. Wil Martens raised this objection in his response to Teubner's paper Transnational Fundamental Rights: Horizontal Effect?, supra note 12. See generally Wil Martens, Human Rights and the Destructive Communications and Actions of Differentiated Society, in 40 REchtsfilosofie \& ReChTSTHEoRie [Legal PhILOSOPHy \& LEGAL THEORY] 246 (2011) (Neth.). 
constitutional question of inclusion and exclusion, both as a question about inclusion/exclusion and as a question about constitutionalism?

\section{II. "You Have No SOVEREIGNTY Where We GatheR"16}

To prepare the way for dealing with these issues, it may be helpful to begin by asking whether the self-constitutionalization of a global sectorial collective releases inclusion and exclusion from its spatial dimension, such that what societal constitutions regulate is only the boundary between a function system and its environment. Let us consider the example of the digitalization of communication, which was introduced in the foregoing section. This example seems particularly apposite because, to the extent that cyberlaw appears to sever the link between "legally significant (online) phenomena and physical location," it would require a novel form of law and legal institutions, one that does not rely on the physical boundaries of real space. ${ }^{17}$ Indeed,

[w]e know that the activities that have traditionally been the subject of regulation must still be engaged in by real people who are, after all, at distinct physical locations. But the interactions of these people now somehow transcend those physical locations. The Net enables forms of interaction in which the shipment of tangible items across geographical boundaries is irrelevant and in which the location of the participants does not matter. Efforts to determine "where" the events in question occur are decidedly misguided, if not altogether futile. ${ }^{18}$

To be sure, the initial euphoria governing the capacity of the regulation of the Internet to extricate itself from the clutches of state law was strongly tempered soon after the publication of the article by David Post and David Johnson. While the architecture of the net initially made it very difficult to regulate relevant behavior, architectures of personal identification and authentication, of content control, and of geographical tracing and zoning had been put into place that allowed state law to re-establish its regulatory purchase on

16. John Perry Barlow, A Declaration of the Independence of Cyberspace, ELECTRONIC FRONTIER FOUND. (Feb. 8, 1996), https://projects.eff.org/ barlow/Declaration-Final.html.

17. David R. Johnson \& David Post, Law and Borders-The Rise of Law in Cyberspace, 48 STAN. L. REV. 1367,1370 (1996).

18. Id. at 1378 . 
Internet activities. ${ }^{19}$ The well-known lawsuit filed in France against Yahoo!, in which the plaintiffs demanded that Yahoo! remove Nazi paraphernalia from its auction site or block access thereto, is a good example of how legal orders set spatial boundaries on Internet activities. ${ }^{20}$ Although the corporation argued that the Internet is a global medium and that it could not block French citizens from Yahoo! sites, the French court not only decided in favor of the plaintiffs, but eventually also threatened the company with a fine of 100,000 French francs for each day of delay in complying with its ruling. ${ }^{21}$ Soon after, Yahoo! installed filters that blocked computers located in France from access to portions of the auction site. ${ }^{22}$ In short, the Net has become eminently regulable.

Teubner's argument for societal constitutionalism and global law does not turn, however, on the technological state-of-the-art and, in that sense, is in no way undermined by these technological developments. To the contrary, he forcefully argues that cases such as Yahoo! illustrate the distortions that ensue when the constitutional problem concerning the conditions of universal access to a communicative medium is leveled down to a territorially oriented approach to inclusion and exclusion. ${ }^{23}$ It is significant, he notes, that the famous Declaration of the Independence of Cyberspace, drawn up by John Perry Barlow, appeals to the rhetoric of constitution-making to highlight the process that is gradually giving shape to a global constitution for digital communication. ${ }^{24}$ More pointedly, Barlow does so in a way that releases the global digital community from the constraints of territorial inclusion and exclusion—or so it seems.

So, let us suppose that the emergence of cyberlaw was marked by a "Declaration" like that penned by Barlow: "Governments of the Industrial World, you weary giants of flesh and steel, I come from Cyberspace, the new home of Mind. On behalf of the future, I ask you of the past to leave us alone. You are not welcome among us. You have no sovereignty where we gather." ${ }^{25}$ In short, imagine the most favorable

19. "The architecture of cyberspace will in principle allow for perfect zoning-a way perfectly to exclude those who would cross boundaries." Lawrence Lessig, The Zones of Cyberspace, 48 STAN. L. REV. 1403, 1409 (1996).

20. UEJF et Licra c/ Yahoo! Inc., Tribunal de Grande Instance [TGI] [ordinary court of original jurisdiction] Paris, Nov. 20, 2000, Juriscom, No. RG 00/05308 (Fr.), available at http://juriscom.net/wp-content/documents/tgiparis20001120.pdf.

21. Id.

22. Id.

23. Teubner, supra note 2, at 3-5.

24. $I d$. at 8-9.

25. A Declaration of the Independence of Cyberspace, supra note 16. 
constellation possible for the (private) self-regulation of the global digital community.

Let us begin with the final sentence of the passage cited from Barrow's exuberant Declaration, turning it into a question: Where do we gather? Where do we gather when, bidding farewell to state sovereignty and its bounded territory, we enact a constitution for global cyberlaw? The Declaration has a ready answer: we gather in cyberspace, which "is a world that is both everywhere and nowhere."26 And it adds shortly thereafter: "We are creating a world where anyone, anywhere may express his or her beliefs, no matter how singular, without fear of being coerced into silence or conformity." 27 So, despite the drastic claim that cyberspace is not the world "where bodies live," 28 what is concretely at stake in the construction of cyberspace is, amongst others, fostering and protecting its potential to secure free speech for embodied beings who are dispersed across the face of the earth, who must type or speak somewhere if they are to gain access to the global cyber-community, and who must glance somewhere at a computer screen or listen somewhere to what someone is typing or saying somewhere. Moreover, the "we" of the cyber-community is, in Barrow's reading, potentially everyone, not, however, as an aggregation of individuals but rather as a whole-as a collective that acts jointly when enacting a constitution such that it is possible to mock state governments because "you do not know our culture, our ethics, or the unwritten codes that already provide our society more order than could be obtained by any of your impositions." 29 In short, and returning to the question, "where do we gather?" it would seem that "where" is everywhere and "we," everyone. So, although technological developments have allowed states to capture cyberlaw to a considerable extent, cyberlaw is the exemplar, at least in principle, of a global legal order, given its capacity to make digital communication available to everyone everywhere.

But would this global legal order be possible without a spatial closure, such that inclusion and exclusion cease to be spatial categories in societal constitutionalism?

Consider the Jyllands-Posten Muhammad cartoons controversy in September 2005. ${ }^{30}$ This controversy casts doubt, to say the least, on the assumption that the global community of Internet users and service providers can reach an agreement on access to cartoons and other

26. Id.

27. Id. (emphasis added).

28. Id.

29. Id. (emphasis added).

30. Greg Hurst, 70,000 Gather for Violent Pakistan Cartoons Protest, Times (Feb. 15, 2006), http://www.thetimes.co.uk/tto/news/world/asia/article2612186.ece (U.K.). 
images of the Prophet Muhammad or, for that matter, of any other prophet. It also calls attention to the question on behalf of whom, and where, Barrow speaks when asserting that "we are creating a world where anyone, anywhere may express his or her beliefs, no matter how singular, without fear of being coerced into silence or conformity." ${ }^{11}$ Now that the Yahoo! case has blazed the way, it is tempting to muster technology to the rescue, implementing filters so that people can be shielded from having to view images of the Prophet Muhammad, thereby also allowing those who are less punctilious to view them if they so wish. The Wikipedia entry on the controversy, for example, helpfully offered instructions on how to modify the user's default browser settings to avoid having to look at images of the Prophet Muhammad on the encyclopedia. ${ }^{32}$ But would this solve the problem that the images have been posted on the Internet, including the web pages of the aniconism-friendly Wikipedia? In the case of groups and individuals for whom aniconism is law, the real problem is not to ensure, by the appropriate technological means, that people can avoid being confronted with images of the Prophet; it is rather that these images are posted at all on the net because "[i]nformation available on the World Wide Web is available simultaneously to anyone with a connection to the global network." ${ }_{33}$ The globality of cyberspace becomes the globality of blasphemy and unbearable affront. The assumption that cyberspace allows freedom of speech to "anyone, anywhere" because it is indifferent to place and person amounts to a de-localization, i.e. the denial and erasure of the bounded spatial configuration of a religious law, and a novel localization, namely, the configuration of a secularized legal space that is spatially bounded because images of the Prophet can be shown anywhere rather than nowhere.

On January 1, 2010, a Somali man "armed with an axe and a knife in either hand"-or so the Danish police claimed-broke down the entrance door of Kurt Westergaard's home in Aarhus and attempted to kill the cartoonist whose drawing lampooning the Prophet in the Jyllands-Posten had given rise to the controversy. ${ }^{34}$ The Somali

31. A Declaration of the Independence of Cyberspace, supra note 16.

32. Talk: Muhammad/FAQ, WIKIPEDLA, http://en.wikipedia.org/wiki/Talk:Muhammad/ FAQ (last visited Nov. 19, 2012) ("If you do not wish to view Muhammad images, you can create an account and read Wikipedia while logged in. User accounts offer a number of preference settings. ... [Y]ou can change your personal settings so that you don't have to see Muhammad images, without affecting other users. This is done by modifying your CSS (Cascading Style Sheet) page, which is individual to each user. To do this ...").

33. Johnson \& Post, supra note 17, at 1375.

34. Somali Charged over Attack on Danish Cartoonist, BBC NEws (Jan. 2, 2010), http://news.bbc.co.uk/2/hi/europe/8437652.stm. 
allegedly was part of the al-Shabab militia. ${ }^{35}$ Where did the man come from when entering Westergaard's home? A BBC news bulletin quotes Sheikh Ali Muhammad Rage, a spokesperson for the group, as saying, "We appreciate the incident in which a Muslim Somali boy attacked the devil who abused our prophet Mohammed and we call upon all Muslims around the world to target the people like [him]." 36 When the Somali man broke down the door with an axe and stepped in, he entered Westergaard's home from one of the places "around the world" to which the spokesperson refers. This is not simply the same world that Barrow calls "our world." When entering, after having broken down the door, the Somali man did more than only cross the legal boundary that separates Westergaard's home from and connects it to the street and, thence, to the rest of Denmark and the other countries joined together into a spatial unity under international law. He also entered from a place outside the interconnected unity of ought-places that make up the legal world inhabited by Westergaard and Barrow.

Indeed, Westergaard's home is an "ought-place" in that it is a place in which, according to the Danish legal order, certain comportment ought to come about, where "ought" means required, prohibited, or permitted. In turn, this space is both linked to and separated from other ought-places such as the sidewalk where, again, certain comportment ought to take place. Boundaries separate these places (e.g. the door leading into and out of Westergaard's home) and are, as such, legal boundaries. Importantly, while legal boundaries separate, they also join ought-places into a more encompassing whole, into a spatial unity, such that, for example, both Westergaard's home and the sidewalk from which the Somali man broke into his home are places within the unity of ought-places that configures the Danish legal order. Also, this legal order has its own legal boundaries that link it to other unities of ought-places such as other states or the sea, which are themselves a higher-order unity of ought-places by dint of their interconnection through international law. ${ }^{37}$ This totality of interconnected ought-places is, strictly speaking, a legal world. When the Somali man entered Westergaard's home to kill him, he did so from an ought-place that has no place in the distribution of ought-places made available in the legal world inhabited by Westergaard and Barrow. The man entered from a strange ought-place that is, as Barrow puts it, not simply "anywhere."

35. Id.

36. Id.

37. Notice that, thanks to international law, the seas are as much legal ought-places as are state territories. The same holds, of course, for the space of space law. 
He entered from elsewhere: from a strange world-a Fremdwelt, to borrow Edmund Husserl's terminology. ${ }^{38}$

Where, then, do we gather when enacting a constitution for global cyberlaw? Somewhere, in a strong sense of the term: in a space that must have an outside-literally. ${ }^{39}$

\section{LAW IN THE FIRST-PERSON PLURAL}

So, on the face of it, it seems that there can be no global cyberlaw, no global digital community, absent a spatial closure that separates an inside from an outside. But what is the nature of this spatial inside and outside? Why, if at all, might it be constitutive for all global law and, in fact, for any legal order we could imagine? What might this tell us about the fundamental sense of inclusion and exclusion that would need to be addressed by constitutionalism, societal or otherwise?

To address these questions we must shift our attention to the "self" of societal self-constitutionalization. This shift is required because, as the reader will remember, Luhmann and Teubner acknowledge that the self-constitutionalization of global society is not oriented toward function systems as such, which do not and cannot organize themselves, but rather toward "organizations." Instead of building on the systems theoretical notion of an "organization," I will draw on analytical studies of collective action and on a phenomenology of strangeness to develop a thumbnail version of what might be called a theory of law in the first-person plural. ${ }^{40}$ To mark this difference, I will refer to legal orders rather than to systems and to collectives rather than to organizations. The reason for this shift of conceptual framework is that it allows us to make spatial sense of what happened on January 1, 2010, when the Somali man entered Westergaard's home to kill him, and, more

38. See generally 3 EDMUND HUSSERL, ZUR PHÄNOMENOLOGIE DER Intersubjektivität: TeXTe AUS DeM NACHLASS [ON THE Phenomenology OF INTERSUBJECTIVITY: LEGACY TEXTS] (1973) (Ger.).

39. For an analogous analysis of the bounded spatiality of multinationals, see generally Hans Lindahl, Alegality: Postnationalism and the Question of Legal Boundaries, 73 MOD. L. REv. 30 (2010). For further analogous analyses, including lex mercatoria and nomadism, see generally HANS LINDAHL, FAULT LINES OF GLOBALISATION: LEGAL ORDER AND THE POLITICS OF ALEGALITY (forthcoming 2013).

40. I draw here, in particular, on MARGARET GILBERT, ON SOCIAL FACTS (2nd ed. 1992) [hereinafter GILBERT, ON SOCIAL FACTS]; MARGARET GILBERT, A THEORY OF POLITICAL OBLIGATION: MEMBERSHIP, COMMITMENT, AND THE BONDS OF SOCIETY (2006); and PHILIP Pettit, A Theory of Freedom: From the Psychology to the Politics of Agency (2001), as concerns collective action and intentionality. With regard to a phenomenology of strangeness, I draw, amongst others, on HUSSERL, supra note 38, and 1.4 BERNHARD

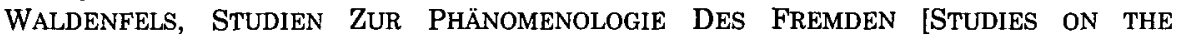
Phenomenology Of StRANGENESS] (1997-1999) (Ger.). 
generally, of the spatial closure which is constitutive of all legal orders, whatever their scale and whatever their kind. The more general question of whether the analysis I will be developing also holds for other kinds of social systems and their "operational closure" may remain an open question for the purpose of this paper.

Let me begin the discussion with some very general considerations about collectives and collective action. Margaret Gilbert introduces a distinction between two uses of the expression "we," which helps to clarify the nature of collectives and their action. Indeed, there is "we, both," as when each of a manifold of individuals happens to watch a stork fly over them, and there is "we, together," as when a group of bird-watchers are out on an expedition and happily call each other's attention to the bird as it flies by. ${ }^{41}$ Only in the second case is there a collective, engaged in collective action. While groups are made up of at least two individuals, their acts are not merely individual acts, and even if there are, there can be no collective acts absent the acts of individuals: we are bird-watching together, not severally. The difference between the two modes of "we" becomes clear if we bear in mind that if we are bird-watching together, then each of the participant agents is entitled to expect that the other agents will alert her to the stork when it flies over and to rebuke them if they do not. 42 The point of their joint action is to engage in bird-watching. No such entitlements attach to "we, both." Indeed, the comportment of individuals under "we, both" has no shared point; "we" functions as an aggregative rather than an integrative concept.

This is a very crude and preliminary exposition of the notion of collectives and collective action. While a much more refined analysis is possible, this exposition suffices for my purposes in this paper. ${ }^{43}$ Indeed, my claim is that legal comportment is a species of the genus collective action. There are obviously other forms of collective action, such as making music together or simply walking together, both of which are canonical examples unpacked by theories of collective action. My point is, simply, that if we want to make sense of legal comportment, then we

41. See GILBERT, ON SOCIAL FACTS, supra note 40, at 168 .

42. The reader might remember the memorable text message sent by Rebekah Brooks, erstwhile editor of Rupert Murdoch's tabloid News of the World, to David Cameron, Prime Minister of the United Kingdom: "We're definitely in this together!" John Plunkett, Rebekah Brooks Texted David Cameron: We're Definitely in This Together!', THE GUARDIAN (June 14, 2012, 8:38 AM), http://www.guardian.co.uk/uk/2012/jun/14/rebekahbrooks-texted-david-cameron.

43. For more detailed analyses of collective action, see generally MICHAEL E. BRATMAN, FACES OF INTENTION: Selected Essays on INTENTION AND AgenCy 93-164 (1999); GIlBert, ON SOcIal FaCTS, supra note 40, at 146-236; Philip Pettit \& David Schweikard, Joint Action and Group Agency, 36 PHIL. Soc. SCI. 18 (2006). 
need to understand it as one particular mode of group action. By the same token, legal entitlements and sanctions (in response to illegal comportment) are a species of the structure of entitlements and rebukes proper to group action in general. Furthermore, and importantly, to the extent that the acts of participants in joint action interlock with a view of realizing the point of their joint action, there is always, however implicitly, a normative dimension in collective action: this is what I ought to do, and that is what you ought to do, under the circumstances, in view of realizing the point of our joint act. The point of joint action is also always a normative point, even though the kind of ought involved in playing music together or walking together or, say, engaging in a contract of sale are different in each case. Significantly, what it is that we ought to do together-the normative point of joint action-may itself be open to discussion and transformation over time. In short, while there are of course a host of nonlegal collectives, there are no non-normative kinds thereof.

Before turning to the problem of closure, let me highlight one way in which this nutshell account of law in the first-person plural perspective is both close to and quite different from a systems-theoretical approach to law. Indeed, whereas systems theory would refer to a "process of communication," a first-person plural account of legal order sees an interlocking web of individual acts-participant agency-the unity of which is intelligible in terms of the normative point of joint action. ${ }^{44} \mathrm{I}$ hasten to add that the two accounts of legal order are not mutually exclusive; the point is, instead, that the third-person sociological account of systems theory presupposes the first-person plural account of legal order, but not vice versa.

There are other similarities and differences between these two approaches, some of which I will explore in the coming pages. But the foregoing suffices to justify by way of a very compact, three-step argument why and in what way legal orders require a closure. First, and summarizing my earlier considerations, legal orders presuppose the first-person plural perspective of a "we" in joint action. ${ }^{45}$ It is this first-person plural perspective to which John Perry Barrow appeals in his Declaration of Independence and, more generally, which is involved in collective self-constitutionalization. Second, there can be no joint agency by a manifold of individuals, whether two or indeterminately many, absent a normative point of their act: that which their joint action is about. Here again, this is what Barrow's Declaration of

44. Niklas LuHMaNN, Social Systems 143-45 (John Bednarz, Jr. \& Dirk Baeder, trans.,1995); GILBERT, ON SOCIAL FACTS, supra note 40, 422-25.

45. Although I cannot discuss this point here, the first-person, plural perspective is not the same as Hart's "internal" perspective. 
Independence illustrates when he asserts that "we are creating a world where anyone, anywhere may express his or her beliefs, no matter how singular, without fear of being coerced into silence or conformity." 46 Acts draw their meaning as legal acts from their inclusion in an interlocking web of acts oriented to realizing a normative point. Third, there can be no normative point in law absent a closure. This closure is material, to the extent that it not only indicates what joint action is about, but also what action is called for to realize a normative point. It is also personal, determining whose action is called for; spatial, establishing where action is called for; and temporal, indicating when it is called for. All legal orders are closed in space, in time, in membership, and in the content of the acts they allow and disallow. While I have been concerned to discuss the spatial and subjective closure required for the emergence of a global Internet community, it would not be difficult to extend the analysis to its temporal and material closure. If who ought to do what, where, and when is intelligible by reference to the normative point of joint action, then conversely these four dimensions of legal action give concrete shape to its normative point, even though they need not exhaust the spatial, temporal, subjective, and material conditions under which the normative point of the apposite joint act can be realized.

What does closure achieve? An answer to this question leads straight to collective identity and its contrasting terms. Following Paul Ricœur, I distinguish between two forms of identity: sameness (idem) and selfhood (ipse). Although Ricœur elaborates on these from the perspective of individual identity, collective identity also involves sameness and selfhood. ${ }^{47}$ Sameness can be parsed into numerical and qualitative identity. The former concerns unity or oneness, as in the expression "one and the same"; its contrasting term is plurality, as when one refers to two or more things. ${ }^{48}$ The latter refers to extreme resemblance; its contrasting term is dissemblance or difference, as when "a" is said to be different to "b." The second form of identity is selfhood. It involves the capacity of agents to view themselves in the first person perspective as the bearers of certain beliefs and the authors of certain actions. ${ }^{49}$ Selfhood speaks to the first-person plural perspective when individuals refer to themselves as members of a group and to the group's intentions and actions by using indexical words such as "we,"

46. A Declaration of the Independence of Cyberspace, supra note 16.

47. PAUl RICOEUR, ONESELF AS ANOTHER 2-3, 115-25 (Kathleen Blamey trans., 1992) (1990).

48. Id at 116 .

49. PETTiT, supra note 40, at 115-19. 
"us," "our," and "ours." The contrasting term for selfhood is, according to Ricœur, other than self-alterity or otherness. ${ }^{50}$

So, returning to our question, closure gives rise to collective identity as sameness and to its contrasting terms. As concerns quantitative sameness, closure brings about numerical identity by giving rise to one legal order, which stands in contrast to multiple legal orders. As concerns qualitative sameness, closure gives rise to a legal collective that is different than other legal orders, and which can itself change, becoming different over time. Notice that theories of legal pluralism appeal to both forms of idem-identity. On the one hand, and trivially, at issue is a plurality of legal orders, many rather than one: the contrast to quantitative identity. On the other hand, and no less trivially, at issue are different legal orders which "co-exist" in a single spatio-temporal context: the contrast to qualitative identity. Importantly, however, the notions of plurality and difference presupposed by theories of legal pluralism also apply, for example, to a basket of assorted fruits, including pears, apples, and bananas. Here also, there is a plurality of "entities," and each of these "entities" is different to the others. To put it another way, oneness and plurality, resemblance and dissemblance, are contrasts which are applicable to all things in a very broad sense of the term "thing," which includes bodies, events, acts, persons, and the like.

Yet, sameness and its contrasts by no means exhaust what closure brings about. Indeed, closure speaks primarily to the emergence of selfhood and otherness. Inclusion and exclusion are actor-categories, categories that make sense from a first-person perspective. So, on the one hand, closure as inclusion gives rise to a collective as an actor: as a "plural subject," to borrow Margaret Gilbert's phrase. ${ }^{51}$ Closure makes it possible for a manifold of individuals to view themselves as a group, the members of which ought to act jointly. In a word, closure not only gives rise to collective identity as sameness, but also to collective identity as ipseity: to a self. 52 On this reading, closure brings about inclusion as a

50. RICOEUR, supra note 47; accord PETTIT, supra note 40 , at 117-18.

51. GILbERT, ON SocIAL FACTS, supra note 40, at 199-200.

52. See here an important difference with systems theory, for which the "autos" of autopoiesis is not equivalent to the self of collective selfhood. More generally, and this is no more than a tentative claim requiring further exploration and development in a later publication, I wonder whether a systems-theoretical approach to law doesn't rely exclusively on identity as sameness, when explaining the identity over time of a legal order, purging collective identity as selfhood from its account. This would not be surprising, granted Luhmann's relentless move to eradicate subjectivity from the concept of a social system. While I would want to join Luhmann in dropping the notion of transcendental subjectivity from a viable account of social orders, including legal orders, this move need not entail jettisoning the concept of subjectivity in the sense of collective agency. 
collective self-inclusion. On the other hand, closure gives rise to a domain of our own. The emergence of collective selfhood goes hand in hand with the emergence of an own space, the bounded unity of places we call ours; an own time, the bounded series of events we call our history; an own content, the bounded unity of interlocking acts we call our joint acts; an own subjectivity, the bounded set of individuals we call our members. As Barrow notes, "you do not know our culture, our ethics, or the unwritten codes that already provide our society more order than could be obtained by any of your imposition." 53

If all of this goes into collective self-inclusion, what is excluded therefrom? What is the contrasting term for collective self-inclusion? In a preliminary formulation, collective self-inclusion goes hand in hand with other-exclusion, that is, with the exclusion of "other than self." But this remains a highly abstract formulation that casts little or no light on what is "other than self" with respect to collectives. No less importantly, otherness is a far broader category than strangeness, which emerged in our account of the global Internet community. By these lights, it remains unclear how the closure that gives rise to a collective also calls forth otherness and strangeness, and, more pointedly, otherness-as-strangeness.

Answers to these questions begin to materialize if we bear in mind that what collective self-closure includes is law, whereas what it excludes is nonlaw. From the perspective of the collective, law is on this side of a self-closure; nonlaw on the other side. Importantly, the first-person plural inclusion of law and exclusion of nonlaw is asymmetrical in at least four decisive ways. First, the divide is drawn from one of the two sides in the very process of giving rise to both, rather than from a third position: we include ourselves as a legal order and exclude the rest as nonlaw. By laying down the broad lines of joint action and its normative point, which means determining who ought to do what, where, and when, the closure that gives rise to a collective is only concerned with establishing what will count for it as law; it says nothing, and can say nothing, about what lies beyond the pale of joint action and its normative point: nonlaw. The divide is also asymmetrical in a second way. What self-closure does is to indicate, at least minimally, what is legally important and relevant to the collective, i.e. what is the normative point that joint action seeks to realize. By contrast, nonlaw is all the rest. It is the collective's other, in a very broad sense: "other than self" to borrow Ricœur's vocabulary. Nonlaw is a residual (rather than negative) category because it encompasses everything that is irrelevant and unimportant with a view to realizing

53. A Declaration of the Independence of Cyberspace, supra note 16. 
the normative point of joint action. All a legal collective can do with respect to nonlaw is to declare tracts of it to be relevant and important, thereby drawing these into the ambit of law, or to declare unimportant and irrelevant what had been part of a legal order, thereby relinquishing it to the domain of nonlaw. Whence a third asymmetry: law is preferred to nonlaw.

These considerations on law and nonlaw, relevance and irrelevance, importance and unimportance, resonate with Husserl's descriptions of a Heimwelt (a home-world), which he sometimes contrasts to an Außenwelt (an outer world). ${ }^{54}$ In an important passage of his posthumously published notes on the phenomenology of intersubjectivity, he formulates this contrast in the form of a question:

Doesn't the world as a environing life-world, hence as a practical environing world, have an unpractical horizon, a [domain of the] non-experienced and non-experienceable, which is not merely 'out of bounds' (ausser Spiel) practically (which would already be practical), but rather a horizon that is not at all in question for praxis?55

Notice that the passage turns on two distinctions that are complementary but irreducible to each other. On the one hand, a home-world distinguishes between action that is in and out of bounds, while comprising both. On the other hand, the home-world has an external horizon that separates it from what Husserl calls an "irrelevant outside": "[T] he practical interest is within (Drinnen)." concerns law, this irrelevant outside, which lies beyond the pale of practical interest because it has been excluded from what is germane to joint action by a collective, is the domain of nonlaw. Whence a fourth asymmetry between law and nonlaw: inside is preferred to outside.

If we reformulate the notion of closure as giving rise to the first-person preferential distinction between order and nonorder, we advance a step further toward clarifying our understanding of closure and the difference between inclusion and exclusion at issue in constitutionalism, societal or otherwise. The distinction is a first-person distinction in that legal orders have the form of collectives whereby a manifold of individuals act together over time. The distinction is preferential in that nonorder functions as the residual domain of what

54. HUSSERL, supra note 38 , at $212,419,656$ (translation by author).

55. Id. at 431 . (translation by author).

56. Id. (translation by author). 
is unimportant. I speak of nonorder, finally, rather than of disorder, because the latter is the privative form of legal order. In contrast with disorder, nonlaw comprises the ambit of the unordered. ${ }^{57}$

A number of aspects of this preliminary characterization of nonlaw require further analysis. The first is that the distinction between law and nonlaw, as described heretofore, is not the massive distinction between law "in general" and nonlaw "in general." Instead, it refers to the distinction between a concrete legal order and what is unordered with respect to that legal order. Indeed, the unordered is a relational concept through and through: if the unordered is what falls beyond the scope of joint action by a collective, then different collectives will have different domains of the unordered. Notice that this includes "overlapping" legal orders, in which the domain left unordered by a collective can be occupied by another collective.

Secondly, and closely related to the first aspect, the unordered is, from the first-person plural perspective of a collective, a legal void. Husserl speaks, in this context, of home-worlds as having an "empty outside" (leeren Draussen). ${ }^{58}$ Whereas a legal order has "the structural form of a filled spatio-temporality," its unordered outside constitutes an "'empty' spatio-temporality." 59 Yet, although empty from the perspective of joint action by a collective, the domain of the unordered makes room for other legal orders, other collectives that organize themselves as legal orders. Returning to our earlier observation, if nonlaw is the "other" of a collective self, then the other of a collective includes its others, that is, other collectives.

A third aspect concerns a legal order as a realm of possibilities. Legal possibilities are a species of practical possibilities, that is, the range of acts available to us, the members of a collective, when acting together in the course of a legal practice: legal com-possibilities. In this vein, law opens up practical possibilities by empowering certain actions and indeterminately many-but not infinitely many-ways of connecting these actions to each other (paying for a tram ride, going into a grocery store, taking your food purchases home in a cab). Moreover, legal possibilities, in the sense of normative empowerments, call forth the possibility of illegality, that is, comportment in breach of what is legally empowered. ${ }^{60} \mathrm{By}$ contrast, and in line with what has been noted

57. See Bernhard Waldenfels, ORder IN The Twilight 3 (David J. Parent trans., 1996).

58. See HUSSERL, supra note 38 , at 431 (translation by author).

59. Id. at 139,236 (translation by author).

60. It is in this sense, I believe that one should read Hans Kelsen's notion of Ermächtigung, which became ever more important in his reformulations of the legal 
above, the unordered is not simply the absence of legal possibilities; instead, the unordered comprises a surfeit, rather than a dearth, of practical possibilities that have been leveled down to the status of the irrelevant and unimportant, as the price that must be paid if there is to be any legal empowerment at all.

A fourth and decisive feature concerns the divide between legal (dis)order and the unordered. In effect, this divide is not posited separately from the boundaries that determine who ought to do what, where, and when. To the contrary, the divide between a legal order and its unordered runs along each of the boundaries whereby a collective establishes who ought to do what, where, and when. Indeed, each boundary drawn by a collective delimits what it deems to be important and relevant, partitioning it from what is unimportant and irrelevant. But because the unordered is a residual category, and as such opaque to joint action by a collective, the divide between a legal order and what it leaves unordered functions differently than boundaries within a legal order. On the one hand, boundaries join and separate such that selecting products one wants to purchase in a grocery store demands understanding how the store's pay-point marks a spatial boundary in both separating the food store from other places within a unity of places and joining it thereto. On the other hand, while the divide between a legal order and its unordered domain runs along this pay-point, as it does along all other spatial boundaries of the apposite legal order, it does not join and separate places in the way boundaries do. Whereas places within a legal order are reversible in that, under the conditions dictated by joint action, a legal agent can move from one to the other and back, there is no such reversibility between legal order and the unordered. ${ }^{61}$

Consequently, qua self, a collective is "in" space and time in a way that is irreducible to how things-including collectives, when viewed as things-are "in" space and time. Theories of legal pluralism are blind to this fundamental difference. Indeed, "in-ness" speaks, in the former case, to the divide between a legal order and its unordered, such that realizing the normative point of joint action by a collective requires a spatio-temporal discontinuity between collective self and other than self. Let me highlight this point by distinguishing between boundaries and frontiers. Whereas there can be no legal boundaries absent a spatial continuity within which different ought-places are differentiated and

“ought." See Hans Kelsen, PuRe Theory of LaW 15-16 (Max Knight trans., U. Cal. Press 1967) (1960).

61. See generally Hans Lindahl, Boundaries and the Concept of Legal Order, 2 JURISPRUDENCE 73 (2011), for a discussion of phenomenology of pay-points as boundaries and as frontiers of a legal order. 
interconnected, frontiers mark the confines of a legal order, hence a discontinuity and an asymmetry between inside and outside. To leave, crossing over into the far side of the frontier, is to abandon what a collective deems to be the space of law; to arrive, crossing over from beyond the far side of the frontier, is to come from an ought-place that has no place in the single distribution of legal places made available by a legal order. In this sense, global legal orders are perforce "bounded" in space. The frontiers of legal orders are a species of thresholds about which Bernhard Waldenfels observes that "there is always a privileged domain from which the threshold itself is crossed, and a shadowy domain from which the forbidden, alarming, and endangering streams forth." 62 A threshold-crossing came about when the Somali man entered Westergaard's home from a place that was elsewhere than in the unity of ought-places that compose the home-world (Heimwelt) in which Westergaard and Barrow dwell; he entered from a strange world-a Fremdwelt.

The threshold-crossing by the Somali man allows us to introduce, however briefly, the notion of strangeness-otherness-as-strangenessinto our account of legal order. Let me lodge two caveats right away. The first is that strangeness is not primarily a "cultural" category; it points to a specific experience of reality from the first-person perspective, whether individual or collective. Secondly, although the notion of strangeness does not figure as such in legal orders in which reality is disclosed on the basis of the distinction between legality and illegality, the experience of strangeness is by no means alien to legal orders. I dub this experience alegality. I hasten to note that alegality is not equivalent to nonlaw, although there could be no alegality in the absence of the unordered. Indeed, alegal comportment is comportment that, having been relegated to the sphere of what a collective views as irrelevant and unimportant, emerges therefrom to question what a concrete collective calls legal (dis)order. More precisely, by questioning how a collective draws the distinction between legality and illegality, alegal comportment questions how it sets the divide between legal (dis)order and the unordered. ${ }^{63}$

This mode of appearance of comportment is what I have sought to grasp with the compound term "alegality." For the one, "legality" in alegality comprises both terms of (il)legality as drawn by a concrete collective: something appears as relevant and important from the perspective of the collective, hence as legal or illegal. For the other, alegality does not merely mean the negation of law, for that would be

62. WALDENFELS, supra note 57 , at 12.

63. A far fuller account of otherness-as-strangeness is offered in LINDAHL, FAULT LINES OF GLOBALISATION, supra note 39. 
legal disorder: the privative manifestation of legal order. Instead, it speaks to other ways of ordering comportment as being important and relevant, despite having been leveled down to what is unimportant and irrelevant for the collective. So, if the "legality" of alegality speaks to a relation between comportment and the collective it challenges, to the extent that comportment registers as relevant because it is (il)legal, the "a" of alegality speaks to a nonrelation between the comportment and the legal order, that is, comportment that raises a normative claim that does not register as normatively relevant from the first-person perspective of the collective. Comportment is alegal because it conjoins both dimensions. This is what took place when the Somali man broke down the front door of Westergaard's home to kill him. His act could be brought into a normative relation with the legal order-was accessible to it-because it could be qualified as legal or illegal; it was an important and relevant act that demanded legal qualification. But the normative challenge the Somali man raised could not be brought into relation with the legal order; his act evoked the importance and relevance of a form of normative empowerment that was practically in-com-possible with the legal order he questioned by seeking to kill Westergaard. In this sense, his act was inaccessible to the legal order: alegal. This, precisely, is what Husserl calls strangeness: "accessibility in its genuine inaccessibility, in the mode of incomprehensibility." 64 That there can be no inclusion without exclusion entails, most fundamentally, that there can be no (il)legality without alegality.

\section{FUNCTIONAL COSMOPOLITANISM AND THE LOGIC OF TOTALIZATION}

We seem to have strayed very far from societal constitutionalism and its concerns when venturing down the path of a theory of law that appeals to analytical accounts of collective action and to a phenomenology of strangeness. In fact, the opposite is true. I have been doing nothing other than outlining what it means that global "sectors" of society must engage in a process of self-constitutionalization. My hunch is that, because it is collectives rather than function systems that constitutionalize themselves, we can no longer take for granted that the "self" of self-constitutionalization is the autos of autopoiesis, nor that this systems-theoretical interpretation of self-(re)production governs how societal constitutions include and exclude. This is certainly not the place to engage in a full-blown analysis of the similarities and differences between a theory of law in the first person and a systems-theoretical approach to law. Instead, my sole concern is to

64. HUSSERL, supra note 38 , at 631 (translation by author). 
establish how a theory of law in the first-person contributes to shedding new light on societal constitutionalism. I concentrate hereinafter on two questions. First, how might this theory demand that we reconsider the role of the inclusion-exclusion distinction in a theory of societal constitutionalism? Second, what interpretation does it offer of inclusion and exclusion as a constitutional question? I address the first of these issues in the present section; the second is addressed in the final section of this paper.

A reader steeped in systems theory will have been struck by a number of similarities between the account of the inclusion-exclusion difference defended by a systems-theoretical approach to societal constitutionalism and that espoused by theory of law in the first person. Here are five salient similarities: (i) There can be no inclusion without exclusion; the difference as such is constitutive for systems/orders. A system or order that would include without excluding ceases to be such. (ii) Operations/acts by systems/orders are operations/acts of drawing the boundary that includes and excludes. This holds both for operations that (re)produce the boundary between a system and its environment and for comportment that (re)sets the divide between a legal order and its domain of the unordered. In other words, identification and differentiation are the two faces of the single operation/act of setting boundaries: to identify is to differentiate and to differentiate is to identify. (iii) The system/order includes what is relevant thereto and excludes what is irrelevant. There is a strong discontinuity between what is included and what is excluded; the former is relevant, the latter irrelevant. This strong discontinuity holds as much for the difference between a system and its environment as for the difference between legal (dis)order and its domain of the unordered. (iv) Regardless of whether one refers to systemic "self-observation" or to the authoritative determination of boundaries from a first-person plural perspective, the closure of a system/order demands second-level operations/acts that monitor and uphold unity as set in first-level operations/acts of inclusion and exclusion. (v) Closure into a system/order is always a closure of possibilities. Indeed, inclusion opens up a finite range of possible operations/actions and combinations thereof, while excluding others. The domain of what is excluded does not speak to the absence of possibilities, but rather to an excess or surfeit of possible acts/operations and combinations of acts/operations, albeit possibilities which are irrelevant for the system/order. Accordingly, both accounts of inclusion/exclusion defend the necessity of the boundary that includes and excludes while also postulating the contingency of how it is drawn.

In each of these ways, a theory of law in the first-person provides strong support for Teubner's claim that the inclusion-exclusion 
difference is the central issue that must be addressed by a theory of law and a fortiori by a theory of societal constitutionalism. But fundamental differences are also concealed in these similarities, differences which, in my opinion, question some of the key presuppositions governing a theory of societal constitutionalism.

The first point of discussion concerns the primordial "locus," as one could put it, of inclusion and exclusion. On Luhmann and Teubner's view, that locus is the function system. First and foremost, function systems include and exclude, even though they must rely on organizations to institutionalize functional inclusion/exclusion. The primordiality of functional inclusion and exclusion becomes fully visible in modernity, in which the emergence of functional differentiation radically transforms the situation of individuals. Indeed,

individuals can no longer be defined by social positions into which they are born. They no longer belong to a partial system of society; they must gain access to all function systems to be able to live in accordance with their demands (anspruchsgemäß). Societal inclusion must accordingly be regulated in a new way .... Since around 1800 the situation is clear, and it involves both care by the function systems as well as participation in them, in both passive and active relations. Everyone has legal capacity; everyone may lay claim to treatment in case of sickness. Everyone must go to school; everyone is affected by political decisions, hence entitled to participate in them. Everyone is capable of receiving and spending money and participates, accordingly, in the economy. In all these respects, equality of opportunities and freedom of choice are insufficiently realized. 65

So, the "realization of these claims (Ansprüche)"66 is the aim of constitutionalizing the inclusion of everyone in each of the function systems, such that these claims can become entitlements-enforceable rights of access to function systems.

To assess this analysis, let us begin with Luhmann's account of the claims raised by individuals in relation to function systems. On his view, the function system itself is the addressee of such claims. ${ }^{67}$ No doubt functions play a role in terms of the content of claims. But surely

65. LUHMANN, supra note 4, at 131-32 (translation by author).

66. Id. (translation by author).

67. Id. at 133 . 
it is a collective, and not a function system, which must be the addressee of claims. In other words, a claim is addressed to a manifold of individuals considered as a unit in joint action. The claim will be relevant to the extent that it impinges on the normative point to be realized by joint action, and irrelevant, hence not even worthy of being taken into consideration, if it does not. By the same token, a claim is only such if it can be accepted or rejected; but acceptance or rejection amounts to a collective decision about who ought to do what, where, and when, that is, about what ought to count as joint action by the collective. So, the very notion of a claim presupposes a collective to which it is addressed, such that "laying claim to the function" 68 amounts to laying claim to certain kinds of comportment as demanded by the terms of joint action. On this reading, a collective is not simply the vehicle or instrument by which function systems address or do not address claims raised by individuals against them; there is nothing "above" or "behind" the collective to which claims are addressed, because to lay claim to a function is simply to demand that a certain comportment take place in accordance with the terms of joint action. ${ }^{69}$

This is not mere semantic correction; it has a capital implication for the entire idea of inclusion and exclusion. Indeed, if all claim-talk is collective-talk, so also is inclusion/exclusion-talk. Inclusion is, first and foremost, inclusion into a collective, and exclusion, exclusion from a collective. Now, inclusion into a collective implies inclusion into the spatial, temporal, subjective, and material dimensions of joint action. This, concretely, is what is involved in access to a "function." To claim a "right to access" to a global "sector" is to claim that one is entitled to participate in joint action by the apposite collective, which means that one claims that one fulfills the criteria for participant agency as concerns its subjective, temporal, spatial, and material conditions. In particular, all access to a "function" is spatial access, hence access to an inside, and subjective access, access to membership.

This is obviously at loggerheads with the view defended by Luhmann and Teubner, for whom the globalization of function systems shows that both of these forms of access are contingent and anachronistic. ${ }^{70}$ It no longer makes sense to speak of inclusion/exclusion in terms of membership when, in a globalized society, everyone, hence

68. Id. (translation by author of "die Funktion in Anspruch nehmen").

69. See Teubner, supra note 14 , at 222 ("The various attempts at global constitutionalism are directed rather at social processes 'beneath' the function systems.") (emphasis added).

70. Niklas Luhmann, Territorial Borders as System Boundaries, in CoOPERATION AND CONFLICT IN BORDER AREAS, 237 (Raimondo Strassoldo \& Giovanni Delli Zotti eds., 1982); Teubner supra note 3 , at 7-8. 
the "entire population," lays claim to the different function systems. By the same token, it no longer makes sense to speak of inclusion/exclusion in spatial terms when law has become global law, that is, a "self-reproducing, worldwide legal discourse which closes its meaning boundaries by the use of the legal/illegal binary code and reproduces itself by processing a symbol of global (not national) validity."71

The whole thrust of a theory of law in the first-person developed heretofore is, however, to reject the assumption that inclusion/exclusion can be understood independently of the fourfold closure governing collective self-constitutionalization.

As concerns space, a collective that would constitutionalize itself must close itself as an inside with respect to an outside, laying claim to a space as its own and vice versa. The reference to an "own" space shows that the inside-outside distinction is ambiguous, as it can mean a domestic space in contrast to foreign spaces and a familiar space in contrast to a strange space. A strange space is intimated by ought-places that have no place in a distribution of places deemed to be a collective's own space, yet which, as ought-places, raise a normative claim of their own. The two modes of the inside-outside distinction are irreducible to each other: a strange place need not be foreign; a foreign place need not be strange. Crucially, while the distinction between domestic and foreign spaces is contingent, the distinction between own and strange places is constitutive of legal order. In this fundamental sense, global legal orders are no less bounded in space than state law, international law, or any other form of law. This is precisely the significance of the Somali man breaking down the front door of Westergaard's home in an attempt to kill him. To return to Teubner's characterization of global law cited above, there is no meaning to closure absent a spatial closure. In short, societal constitutions must rely on inclusion and exclusion as spatial categories if they want to be societal constitutions.

Comparable considerations apply with respect to membership. On Luhmann and Teubner's account, the liberation of function systems from the tutelage of states and their territorial boundaries implies that everyone, independent of membership in a political collective, can, in principle, lay claim to what function systems have to offer: "everyone may lay claim to treatment in case of sickness. Everyone must go to school."72 And, returning to the example of a global digital community, its constitutionalization must guarantee a "universal . . right of access to digital communication."73 Yet, regardless of their "scale," collectives

71. Teubner, supra note 3 , at 12 (emphasis removed).

72. LUHMANN, supra note 4 , at 132.

73. Teubner, supra note 2 , at $3-4$. 
necessarily call forth bounded membership in the form of participant agency. Because participant agency is defined in terms of the realization of the normative point of joint action, also participant agency that involves what is prima facie "the entire population" of the earth necessarily involves bounded membership, even if the boundary may remain initially concealed. But this boundary becomes visible in the face of comportment that radically contests the normative point of joint action by a collective that putatively gathers together everyone. Is not such a contestation of a global legal order at the heart of the Somali man's attempt to kill Westergaard? What is most interesting about this case is not that he rejects being included in a global digital community; this could easily be accommodated by a theory of societal constitutionalism in terms of the individual's freedom of choice to give form to his personal identity by deciding whether or not to make use of a constitutionally guaranteed right of access to digital communication. Instead, the whole point of the Somali's act was to contest, on normative grounds, that anyone may be allowed to engage in digital communication involving images of the Prophet Muhammad or of any prophet, for that matter. This claim (Anspruch) is irreconcilable with the claim raised by Westergaard, Barrow, and their liberal brethren of constitutionalizing freedom of digital communication. So, who belongs to the "we" who gathers somewhere to enact a cyber-constitution? Many people scattered across the face of the earth belong to the "we," but not the entire population. To put it provocatively, the "we" that would enact a cyber-constitution (or any other constitution of a global sector) cannot be the entire population if it is to be a whole in action.

This insight has an important implication as concerns Teubner's conceptualization of globalization. "Globalisation," as he puts it, "does not mean simply global capitalism, but the worldwide realisation of functional differentiation." 74 So conceived, globalization has two corollaries, to which I referred earlier in this paper. First, to the extent that function systems become global, they are no longer hemmed in by spatial boundaries, which, in turn, are indispensable to secure subjective boundaries such as membership in a collective. Once function systems liberate themselves from the spatial tutelage of the territorial state, the conditions are created for universality, that is, for access by the entire population to each function system. Second, the globalization of functional differentiation means that the universality of inclusion is partial, inasmuch as inclusion is in each case inclusion within a given function system. These two features allow Luhmann and Teubner to argue that systems theory can endorse globalization while also, in their

74. Teubner, supra note 2 , at 14 . 
view, opposing a logic of totalization. ${ }^{75}$ Accordingly, partial universalization allows them to defend the "unfinished project of modernity" without having to pay the price of postulating a global polity as the condition for its completion. ${ }^{76}$ Whereas Jürgen Habermas and other proponents of a global polity effectively advocate a form of political cosmopolitanism, Luhmann and Teubner champion the completion of the project of modernity in the guise of a functional cosmopolitanism.

A theory of law in the first person casts doubt on this strategy. Certainly, bounded state territoriality is contingent, as is state citizenship. But there can be no process of collective self-constitutionalization, global or otherwise, absent a closure that is spatial as much as it is subjective. Regardless of their "scale," collectives call forth a spatial boundary separating inside from outside in the form of the frontier between the differentiated interconnection of ought-places required to realize the normative point of joint action by the collective and ought-places that are practically in-com-possible with that spatial unity. By the same token, and regardless of their "scale," collectives call forth bounded membership in the form of participant agency. Essentially, globalization changes nothing with respect to inclusion and exclusion. To the contrary, it is only a distraction.

Hence, I am worried that Teubner's interpretation of globalization as partial universality entrenches, in its own way, the logic of totalization his theory of societal constitutionalism seeks to leave behind. Even though he emphatically defends the partiality of function systems as a way of parrying the charge of totalization, he effectively continues this logic by assuming that societal constitutions can create the conditions for all-inclusiveness, albeit restricted in each case to the respective globalized function system. What holds for Habermas also holds for Teubner: the aspiration to universality is the aspiration to totalization. A theory of societal constitutionalism seems to be animated, no less than the cosmopolitan theories it opposes, by a teleological conception of rationality aimed at realizing all-inclusiveness, even if limited to functional all-inclusiveness. More pointedly, one may wonder whether a theory of societal constitutionalism does not claim to draw its normative force from its attempt to hold on to universality and all-inclusiveness, even though-and perhaps because-it proclaims the partiality and irreducible plurality of function systems. ${ }^{77}$

7.5. LUHMANN, supra note 7, at 625.

76. Habermas AND THE UNFINISHEd PROJECT OF MODERNITY (MAURIZIO PASSERIN D'ENTRÈVES \& SEYLA BENHABIB eds., 1997).

77. It is significant, in this respect, that a systems-theoretically inspired sociological study of the "stranger" argues that, "at the end this society is a global society, and that 
If one is to move beyond a logic of totalization, it is not enough to argue that there can be no inclusion without exclusion; one must take the further step of acknowledging that there can be no inside without an outside-literally. This means acknowledging that there is a domain of the strange that is irreducible to and refuses assimilation into what a collective, whatever its "scale" and normative point, would call its own space and its own membership. ${ }^{78}$

\section{CONSTITUTIVE AND Limitative RULES}

The foregoing considerations concentrated on the concept of inclusion and exclusion that follows from the self-constitutionalization of collectives. I would now like to approach inclusion/exclusion as a properly constitutional question: In what way does the account of inclusion/exclusion that has emerged in the foregoing pages shed light on the concept of a constitution, whether of a global collective or otherwise?

Remember, in this respect, the core insight of Teubner's theory of societal constitutionalism: constitutions are composed of constitutive and limitative rules, that is, rules which grant access to a communicative medium and rules which limit the expansiveness and self-destructive potential inherent to all function systems. If the former rules secure the individual's inclusion in function systems, the latter rules protect the individual's autonomy against encroachment by function systems. The assumption underpinning this insight is that constitutions concern the regulation of function systems, not of states. As long as the state captured the regulation of function systems, the (societal) scope and (constitutive and limitative) purport of constitutions could remain concealed; the globalization of function systems, by

means that it no longer has a social outside, that there is no longer anyone that one could legitimately call a stranger to society." See RUDOLF STICHWEH, DER FREMDE: STUDIEN ZU SOzIOLOGIE UND SOzIALgeschichte [THE ForeIGNER: STUDIES ON SOCIOLOGY AND SOCIAL HISTORY] 174 (2010) (Ger.) (translation by author).

78. It will be objected that a legal order enacted by all humankind and for all humankind is conceivable, hence a legal order without an outside. The problem, however, lies in the representational structure hidden in the notion of "a legal order enacted by all humankind." To begin with, "all" functions here as a "we (all) together" not as "we, each (and all)." But this "we (all) together" presupposes a representation claim whereby someone, who has not and cannot have been authorized to this effect, acts on behalf of humanity as a whole in the very process of determining what counts as "human" for the purpose of enacting the legal order. In other words, the (putative) representational act that gets the legal order going also has to determine, at least minimally, what defines "our common humanity" as the normative point of joint action. Inclusion and exclusion have already begun, and so also, Habermas notwithstanding, a Weltaußenpolitik-a world of external politics. 
contrast, discloses their true scope and purport and paves the way for societal constitutions.

As noted at the outset of this paper, I find compelling Teubner's thesis that constitutional theory urgently needs to relinquish its fixation on state constitutionalism if it is to avoid a reductive reading of constitutions and their significance for global law. ${ }^{79}$ No less compelling, or so I think, is his thesis that the inclusion-exclusion difference is the "constitutional question" par excellence. ${ }^{80}$ Far less compelling, to my mind, is the further thesis that the task for constitutional theory would be to make sense of self-constitution and self-limitation along functional lines. ${ }^{81}$ For if it is collectives, not function systems, which constitutionalize themselves, then the way to go is to inquire what it is in collectives that calls forth constitutionalization, then to ask whether and how the emergence of global collectives might pose new challenges for constitutions and a theory of constitutionalism in a global setting. So, my question comes down to this: In what way does everything that has been said about inclusion/exclusion in the first-person plural perspective both explain and demand the constitutionalization of collectives, global or otherwise? In particular, how might they shed light on Teubner's proposal to view constitutions as composed of constitutive and limitative rules?

A first step toward an answer is, I submit, that there can be no collective self-regulation absent a constitution. More precisely, the argument for the constitutionalization of collectives is an argument about collective self-identity as identity over time. In the same way that something-a stone, a house, a tree-can be re-identified insofar as it remains (more or less) the same over time, so also selfhood, as a form of identity, entails permanence in time, even though irreducible to the form of a substratum or substance. ${ }^{82}$ Ricour and Philip Pettit characterize the temporal continuity of self-identity in similar ways. For Ricœur, the paradigm of self-identity is keeping one's word, such that, regardless of the vicissitudes an agent encounters after promising something, the agent nonetheless makes good on her promise by doing that to which she had committed herself. ${ }^{83}$ For Pettit, "[t]he agent will be the same self as the person they were at an earlier time just so far-and this will be a matter of degree-as they actively own or endorse the claims and attitudes and actions of that earlier agent." 84

\footnotetext{
79. TEUBNER, supra note 1 , at 51-58.

80. Teubner, supra note 2 , at 4.

81. TEUBNER, supra note 1 , at $75-87$.

82. RICOEUR, supra note 47 , at 118 .

83. Id.

84. PETTIT, supra note 40 , at 85 .
} 
Analogous considerations hold for collectives, which display self-identity in the form of inter-temporal commitment. "[T] he words defended in the past . . . will stand out for those of us in the collectivity as words that "we' as a plural subject maintain." 85 Collective self-identity is that mode of identity in which a group agent sticks to its commitments over time and which is fit to be held to its commitments.

A collective, when sustaining itself over times as a self, commits to the realization of the normative point of joint action by its members. Now, that to which a collective commits, when sustaining itself over time as a self, is that its members shall realize the normative point of joint action. In other words, a collective perdures as a self over time to the extent that participant agents fulfill what are deemed to be mutual expectations concerning who ought to do what, where, and when in light of the normative point of joint action. But questions are bound to arise along the way about what ought to count as the normative point of joint action and, more radically, about whether there is any normative point of joint action, such that a manifold of individuals ought to view themselves as a collective.

These are precisely the kinds of issues that imperil collective selfhood as identity over time. To deal with such situations, a collective puts into place second-level authorities, whereby certain individuals, acting on behalf of the group, (i) monitor joint action as concerns its normative point and consistency over time, and (ii) take steps to uphold joint action when its normative point is breached or when the consistency of joint action over time is otherwise undermined or threatened. I speak of "second-level" authority because joint action authorizes or empowers certain individuals to engage in certain comportment at certain times and in certain places with a view to realizing the normative point of joint action. This first-level authority to engage in participant agency is backed up by second-level authorities, who also engage in participant agency within joint action, but in the twofold sense of (i) and (ii) noted above. Obviously, it is possible to put into place third-level or even higher-level authorities to monitor and uphold participant agency by the lower level authorities. This tiered structure of authority is what allows for collective self-regulation over time; it affords a more or less robust self-identity to a collective, which perdures over time as a collective self, that is, as a unity in action.

If we look at collectives along these lines, then it becomes clear what a constitution is and why it is demanded by certain forms of joint action. ${ }^{86}$ On my reading, a constitution is the set of rules which

85. Id. at 117 .

86. I say "certain" forms of joint action because not all collectives involve second-level authorities: if you and I take a walk together, to borrow the canonical example of theorists 
empower or authorize joint action, in particular second-level authority or participant agency. In a word, a constitution is the set of rules that make possible collective self-regulation over time. Let me call this, in line with Teubner's favored usage, the "constitutive" role of constitutions. Notice that, on this reading, a constitution is by no means limited to states; to the contrary, state constitutions, as they have emerged in modernity, are but a specific, historically contingent manifestation of the constitutive role of constitutions.

What does this constitutive role have to do with inclusion/exclusion? Everything. For if the emergence of joint action presupposes a closure which brings about collective self-inclusion and other-exclusion, then the constitutive rules of constitutions are the rules oriented to monitoring and upholding the divide that separates legal (dis)order and its domain of the unordered. But this is nothing other than the divide between what is included and what is excluded. First-level participant agency re-identifies the collective self, to the extent that comportment meets mutual expectations about who ought to do what, where, and when; to this extent also, first-level participant agency differentiates the collective from other than self, as that which is simply irrelevant to joint action and its normative point. Second-level participant agency-authority in the strong sense-establishes what ought to count as joint action in the face of questions about its normative point, which arise in the course of first-level participant agency. That is, second-level participant agency re-identifies a collective self and differentiates it from other than self by establishing what ought to be relevant to joint action, whether in the form of legal or illegal comportment.

Accordingly, the constitutive rules oriented to monitoring and upholding the divide between legal (dis)order and its domain of the unordered are rules of collective decision-making concerning what ought to be included and what ought to be excluded from joint action. The corollary of this insight is that, in light of questions concerning what ought to count as joint action with a view to realizing its normative point, collectives can declare tracts of the unordered to be relevant and important, thereby drawing them into the ambit of law, or to declare unimportant and irrelevant what had been part of a legal order, thereby relinquishing it to the domain of the unordered. Hence, constitutive rules work both ways: they can bring about greater inclusiveness by empowering or authorizing comportment that had hitherto been disempowered or a greater exclusiveness by disempowering and de-authorizing comportment that had been authorized and empowered

of collective action, and in the course of our promenade cannot agree where we should go, we simply part ways. Legal collectives, by contrast, do involve such second-level authorities. 
under law. Both shifts presuppose that there is a gap between the normative point of joint action and joint action as posited in a legal order. On this reading, the central task of fundamental rights, as part of the constitutive rules of a constitution, is to expose law as a default setting of joint action and its normative point. From this perspective, fundamental rights aim to show that more is possible, in the way of collective self-regulation, than what a legal order has realized.

To summarize my argument thus far, constitutions as "constitutive" rules are a necessary and irreducible feature of any collective that would seek to secure its permanence over time in the face of questions about joint action and its normative point. States, to reiterate my earlier point, are but one form of such collectives, in the same way that state constitutions are but one way of organizing the constitutive rules of such collectives.

Does a theory of law in the first-person plural perspective offer support for Teubner's thesis that, in addition to constitutive rules, constitutions also include "limiting" or "restraining" rules? Might a theory of law in the first-person plural perspective also accommodate this insight?

I think it does, albeit not in the sense that societal constitutions limit the expansive and self-destructive potential of function systems. Collective self-restraint, for a theory of law in the first person, amounts to restraint with respect to alegality. As conceptualized heretofore, alegal comportment is comportment that calls into question the way in which a collective draws the distinction between legality and illegality; in other words, it challenges what a collective deems to be legally relevant, advancing the claim that what has been excluded from joint action as irrelevant is normatively relevant, even though it cannot be accommodated in its own terms in the legal order it calls into question. This was the upshot of the attempt by the Somali man to kill Westergaard: his action is both relevant and irrelevant, accessible and inaccessible, to the authorities called upon to judge his comportment, to the extent that killing Westergaard is a practical possibility called forth by values that are practically in-com-possible with the values underpinning the liberal freedom of expression protected by the Danish constitution and a fortiori by the "societal constitution" of the global digital community envisaged by Barrow and his brethren.

In such situations, collective self-restraint amounts to acknowledging, albeit indirectly, that alegal comportment raises a normative claim that remains unaddressed in its own terms because comportment must be qualified as legal or illegal in terms of the collective's own normative point. Collective self-limitation is, strictly speaking, an acknowledgment of the limited mode of existence of a 
collective self: alegal comportment is comportment that confronts the collective self it with its limited normative possibilities because there are normative possibilities beyond that limit, yet possibilities that are in-com-possible with its own normative possibilities. A collective ceases to engage in self-restraint, by contrast, when it refuses to acknowledge that there is a normative claim that is being raised against the collective, such that the collective qualification of the comportment as (il)legal exhausts the latter's normative significance.

"Homo sum, humani nihil a me alienum puto," or "I am a man, I consider nothing that is human alien to me," runs the famous line in Terence's play, The Self-Tormentor. ${ }^{87}$ It is perhaps not exaggerated to state that this line encapsulates the cosmopolitan aim of realizing an all-inclusive collective grounded in the humanity of human rights. But because strangeness is an irreducible phenomenon of social life, whoever endorses this tenet inevitably ends up endorsing its inverted form: what is strange or alien is inhuman. The consequence is predictable: why should a collective-including the Danish collective or the global digital community that would realize functional cosmopolitanism-restrain itself when confronted with inhuman comportment?

An alternative begins to delineate itself when one acknowledges, against the claim that nothing human is strange and against the claim that what is strange is inhuman, that, paradoxically, the strange is human. Would it not be in this paradoxical way that we would need to understand the "humanity" of human rights? The implication of this insight would be that the "humanity" of human rights not only appeals to what a collective already includes or can include as its own normative possibilities, but also to those normative possibilities that are definitively excluded from the scope of joint action because they are in-com-possible with its own possibilities, that is, with its self-regulation. It is in this sense, I think, that the Somali man could invoke human rights when defending himself of the charge of attempted murder. And it is perhaps in this sense that human rights are part and parcel of constitutions, societal or otherwise, that is, as rules for collective self-restraint.

87. TERence, THE SELF-ToRmentor 140 (Henry Thomas Riley trans., 1896) (translation altered), available at http://www.gutenberg.org/files/22188/22188-h/files/teren ce3_4.html. 